\title{
Those who do not remember the past are condemned to repeat it
}

\author{
Prem S. Shekar, Daniel Rinewalt \\ Division of Cardiac Surgery, Brigham and Women's Hospital, Boston, MA, USA \\ Correspondence to: Prem S. Shekar, MD. Division of Cardiac Surgery, Brigham and Women's Hospital, Assistant Professor of Surgery, Harvard \\ Medical School, Boston, MA, USA. Email: pshekar@bwh.harvard.edu.
}

\begin{abstract}
Transcatheter aortic valve replacement (TAVR) for aortic valve stenosis has rapidly progressed from its initial application in the inoperable or high-risk patients to those determined to be intermediate and low risk. It is our concern this has occurred without adequate knowledge or examination of the long-term durability of TAVR valves and the impact on subsequent aortic valve surgery, should it be required. In this editorial, we provide insight and reflect upon lessons learned from past surgical techniques and their subsequent abandonment.
\end{abstract}

Keywords: Transcatheter aortic valve replacement; long-term; intermediate risk; opinion

Submitted Sep 22, 2017. Accepted for publication Sep 25, 2017.

doi: 10.21037/acs.2017.09.17

View this article at: http://dx.doi.org/10.21037/acs.2017.09.17

As I sit down to write this short-invited commentary on the future of transcatheter aortic valve replacement (TAVR), the quote from George Santayana comes to mind time and again. While many may view this as being unfavorable towards an evolving technology or as the reflections of someone who does not want to move into the future, it is sincerely far from that. I have been an active part of these developments for the last several years and have strongly supported the addition of novel products and techniques that advance our field and make our patients' lives better. However, we should take a moment to reflect on our past, the lessons learned and contemplate how we can prevent the same mistakes from occurring once again.

TAVR has been an absolute godsend for patients that were inoperable or deemed high risk for open heart surgery. For this initial cohort of patients included in the original PARTNER trial (1), TAVR was a very good solution and continues to be one. While the benefits of TAVR are well established in these patients, we would have done ourselves a great deal of benefit by deciding against using a non-inferiority model in the intermediate risk arm of the trial (2), as the ability to show superiority would have had more of an impact. We have already realized the disadvantages of leaving more than mild aortic valve regurgitation post TAVR (3), emphasizing the need to thoroughly evaluate our results.
More importantly, the intermediate risk patients have not yet reached long term follow up, therefore, the longevity of the valve in this and ultimately in the low risk cohort is currently unknown. We have aggressively extended this technology to these patients without fully understanding the future consequences, and I wonder what difficulty we will encounter if it becomes necessary to remove these prostheses in the future when circumstances will not allow for a valve in valve procedure. Will these prostheses become so embedded into the left ventricular outflow tract and the wall of the aortic sinuses that a complex aortic root procedure would be required?

Two similar instances from the cardiac surgical past come to mind; the first is the use of the stentless porcine valve as an aortic valve bioprosthesis. There was a period in the late 1990's when stentless aortic valve prostheses became widely utilized, with several papers reporting the benefits of lower gradients along with reduction of LV hypertrophy and reverse remodeling contributing to their popularity (4-8). Surgeons began to realize however, that when a reoperation was necessary, the explantation of a stentless porcine valve was extremely difficult, such that it converted a re-operative aortic valve replacement into an aortic root replacement with a subsequent increase in mortality (9). So heinous was the reoperation that it eventually led to the abandonment of the stentless porcine valve as a commonly used viable 
alternative in aortic valve replacement.

The second example is the aortic homograft, which was previously being promoted as an alternative in patients with aortic valve disease, more commonly in the form of a root replacement or occasionally as a subcoronary implant $(10,11)$. Many of these were performed at various highvolume centers throughout the 1990's, however now 15 to 20 years later, we have come to the realization that the homograft was more of a curse than a blessing in an elective patient. Quite like the experience with the stentless porcine valves, the reoperation to address homograft aortic valve insufficiency or stenosis was considerably challenging and unfortunately with increased morbidity and mortality (12-15). Many of these required complex reoperations and innovative techniques, like the modified Cabrol, creating a highly complicated and morbid procedure that was time consuming and claimed many lives in what otherwise would have been a routine re-operative aortic valve replacement. Surgeons no longer use the homograft for routine aortic valve replacements reserving it only for complex aortic root endocarditis.

We must closely examine the application of TAVR in low and intermediate risk patients and be certain that we are truly doing less harm in the long term, when a thoroughly investigated surgical option already exists. It is worth mentioning that in the modern era, surgical AVR can be performed with excellent results and minimal morbidity, with the option for mechanical valves in younger patients that may last them forever.

In our drive to make this technology more amenable to transfemoral or transsubclavian access, we may well be compromising the durability of the bioprosthesis by attempting to crimp it onto increasingly smaller catheters. This could have a detrimental effect on the biological material and affect the longevity of these prostheses.

Additionally one wonders why there continues to be an active pursuit in the development of newer and more refined surgical aortic valves and sutureless surgical aortic valves. If the research and development should indicate that the TAVR would eventually replace surgical aortic valve replacement, then the need to develop advanced versions of these surgical products would be unnecessary.

There is certainly a definitive role for TAVR in those patients determined to be inoperable or high risk. I caution its role as a routine procedure for intermediate and low risk patients, especially when we consider the known longterm outcomes of surgical aortic valve replacement in these cohorts and the unknown long-term outcomes of
TAVR. I wonder if we may be, once again, leaving a legacy of disastrous operations for our younger colleagues in the future, based on our own past experiences.

\section{Acknowledgements}

None.

\section{Footnote}

Conflicts of Interest: The authors have no conflicts of interest to declare.

\section{References}

1. Leon MB, Smith CR, Mack M, et al. Transcatheter aortic-valve implantation for aortic stenosis in patients who cannot undergo surgery. N Engl J Med 2010;363:1597-607.

2. Leon MB, Smith CR, Mack MJ, et al. Transcatheter or Surgical Aortic-Valve Replacement in Intermediate-Risk Patients. N Engl J Med 2016;374:1609-20.

3. Lerakis S, Hayek SS, Douglas PS. Paravalvular aortic leak after transcatheter aortic valve replacement: current knowledge. Circulation 2013;127:397-407.

4. Del Rizzo DF, Goldman BS, Christakis GT, et al. Hemodynamic benefits of the Toronto Stentless Valve. J Thorac Cardiovasc Surg 1996;112:1431-45.

5. Jin XY, Zhang ZM, Gibson DG, et al. Effects of valve substitute on changes in left ventricular function and hypertrophy after aortic valve replacement. Ann Thorac Surg 1996;62:683-90.

6. Westaby S, Jin XY, Katsumata T, et al. Valve replacement with a stentless bioprosthesis: versatility of the porcine aortic root. J Thorac Cardiovasc Surg 1998;116:477-84.

7. Yun KL, Sintek CF, Fletcher AD, et al. Aortic valve replacement with the freestyle stentless bioprosthesis: fiveyear experience. Circulation 1999;100:II17-23.

8. David TE, Puschmann R, Ivanov J, et al. Aortic valve replacement with stentless and stented porcine valves: a case-match study. J Thorac Cardiovasc Surg 1998;116:236-41.

9. Borger MA, Prasongsukarn K, Armstrong S, et al. Stentless aortic valve reoperations: a surgical challenge. Ann Thorac Surg 2007;84:737-43; discussion 743-4.

10. O'brien MF, Harrocks S, Stafford EG, et al. The homograft aortic valve: a 29-year, 99.3\% follow up of 1,022 valve replacements. J Heart Valve Dis 2001;10:334-44; 
discussion 335.

11. Kirklin JK, Smith D, Novick W, et al. Long-term function of cryopreserved aortic homografts. A tenyear study. J Thorac Cardiovasc Surg 1993;106:154-65; discussion 165-6.

12. Byrne JG, Karavas AN, Aklog L, et al. Aortic valve reoperation after homograft or autograft replacement. J Heart Valve Dis 2001;10:451-7.

13. Kowert A, Vogt F, Beiras-fernandez A, et al. Outcome

Cite this article as: Shekar PS, Rinewalt D. Those who do not remember the past are condemned to repeat it. Ann Cardiothorac Surg 2017;6(5):538-540. doi: 10.21037/ acs.2017.09.17 after homograft redo operation in aortic position. Eur J Cardiothorac Surg 2012;41:404-8.

14. Nowicki ER, Pettersson GB, Smedira NG, et al. Aortic allograft valve reoperation: surgical challenges and patient risks. Ann Thorac Surg 2008;86:761-8.e2.

15. Joudinaud TM, Baron F, Raffoul R, et al. Redo aortic root surgery for failure of an aortic homograft is a major technical challenge. Eur J Cardiothorac Surg 2008;33:989-94. 